\title{
¿Patrimonio Natural o recurso productivo? El conflicto ambiental en Sierra Pelada en torno al buitre negro ${ }^{1}$
}

\section{Natural Heritage or Productive Resource? The Environmental Conflict Regarding the Black Vulture in Sierra Pelada}

\author{
Félix Talego \\ Universidad de Sevilla \\ ftalego@us.es \\ Ángel del Río \\ Universidad Pablo de Olavide \\ adelsan@upo.es \\ Agustín Coca \\ Universidad Pablo de Olavide \\ acocper@upo.es
}

\section{RESUMEN}

Analizamos el conflicto que desde 1970 se mantiene entre diversos actores acerca de una de las más importantes colonias de buitre negro (Aegypius monachus) de la Península: entre los partidarios de los eucaliptos y los partidarios de los buitres. Se trata de un conflicto a la vez patrimonial y ambiental. Veremos cómo el buitre negro a un lado y el eucalipto al otro han llegado a ser ejes de un simbolismo que confronta el paradigma productivista y el ecologista en sus respectivas jerarquías valorativas.

Palabras clave: Patrimonio natural; Recurso; Conflicto ambiental; Ecologismo; Productivismo.

\section{SUMMARY}

We seek to analyse the conflict that has existed since 1970 between different social players regarding one of the major black vulture colonies (Aegypius monachus) in the Iberian Peninsula: between those who defend the eucalyptus plantations and those supporting the black vulture. The conflict is both about heritage and the environment. We will see how the black vulture on the one side, and the eucalyptus on the other, have become the lynchpin of a symbolism that confronts the paradigm of productivism and environmentalism in their respective evaluative hierarchies.

Key words: Natural Heritage; Environmental Conflict; Ecologist Movement; Productivism.

\footnotetext{
${ }^{1}$ El artículo es fruto de una investigación financiada por el Centro de Estudios Andaluces en los años 2013 y 2014. 


\section{INTRODUCCIÓN}

Sierra Pelada es una porción del territorio de Sierra Morena Occidental, de unas doce mil hectáreas de extensión. Es el escenario de un "conflicto patrimonial" - podemos decir también "ambiental» — que viene librándose desde hace cuarenta años. En 1989 fue declarado Paraje Natural por la Junta de Andalucía. Constituye un hito en el freno a la extensión del monocultivo maderero y, simultáneamente, un hito en los esfuerzos por evitar la extinción del buitre negro, una especie protegida y reconocida Patrimonio Natural por la Administración andaluza. Los distintos actores implicados mantienen visiones distintas sobre el valor, el significado y el destino de dicho espacio y los elementos que contiene. Posiciones inconciliables en el sentido preciso de que, aunque todos reconocen los valores y significados que los demás atribuyen a aquel territorio (paisajístico, productivo, ecológico, cinegético), cada uno construye una jerarquía valorativa diferente. De manera que los arreglos y ententes que se han venido produciendo no anulan el fondo del conflicto.

En el caso que estudiamos, ese conflicto — ambiental, patrimonial - se cataliza en el buitre negro y el eucalipto. La trama de significados a ellos atribuidos, y su interacción, muestran la trascendencia política del caso. Pretendemos contribuir al entendimiento de aquellos conflictos ambientales en los que algunos de los actores reivindican la cualidad de patrimonio natural para especies o espacios.

La atribución de calidad patrimonial a especies o espacios arranca a finales del siglo XIX con los primeros parques nacionales. Si bien, en aquellos primeros parques el valor monumental primaba sobre el medioambiental (Pérez 2003: 59), que descollará a partir de los años sesenta del siglo XX en los "Santuarios naturales". Estudiamos la contraposición entre "patrimonio natural" y "recurso"; sobre qué debe ser considerado patrimonio (fin) y qué recurso (medio).

Hemos hecho etnografía con los agentes forestales, propietarios del entorno del Paraje, empleados de las empresas madereras y con los ecologistas en Sierra Pela$\mathrm{da}^{2}$, las personas empeñadas en salvaguardar los buitres, lo que ha dado pie a que reflexionemos sobre el ecologismo. Argumentamos que es portador de un nuevo paradigma, alternativo al productivista o "crecentista", que supone la reconsideración radical de qué es patrimonio y qué recurso y conduce a un cierto "reencantamiento" de determinados espacios y especies: nuevas formas de zoolatría, fitolatría y topolatría.

\footnotetext{
${ }^{2}$ El trabajo de campo forma parte de un proyecto más amplio para el estudio de diversas áreas protegidas en Andalucía. Fue subvencionado por la Dirección General de Bienes Culturales de la Junta de Andalucía (2011) y por el Centro de Estudios Andaluces (2012). Se llevó a cabo entre 2011 y 2013, con estancias periódicas en Aroche, desde dónde concertábamos entrevistas con actores de distintas localidades colindantes del Paraje. Procuramos que las entrevistas a propietarios, agentes forestales y ecologistas se hicieran en su entorno laboral, en un contexto más amplio de convivencia y seguimiento de sus rutinas en el Paraje o su entorno. Las entrevistas y conversaciones informales con los empleados de las empresas madereras se realizaron en sus domicilios y lugares de sociabilidad habitual en los pueblos colindantes.
} 


\section{EL LUGAR Y LOS BUITRES}

Sierra Pelada es un Paraje Natural ${ }^{3}$ en Sierra Morena occidental. Su paisaje es característico de la dehesa tradicional, escasamente poblado, por ser tierra de frontera con Portugal hasta el siglo XVIII. Es declarado Paraje Natural en 1989 por alojar una de las principales colonias de buitre negro de la Península. En 1950 comenzaron las repoblaciones con pinos y eucaliptos, la apertura de pistas forestales y la "limpieza" del monte bajo y superficies arbóreas mediterráneas. Estos árboles de crecimiento rápido supusieron una novedad total en la sierra. Llegaron las empresas madereras, que giraban en torno a la Empresa Nacional de Celulosas (ENCE), en un cruce de intereses público-privados (Veiras y Soto 2011). En 1992 la Administración andaluza abandona la repoblación con eucaliptos. No obstante, las empresas madereras continúan en terrenos privados y repoblando con eucaliptos y pinos.

El buitre negro es de conducta esquiva, abandonando los nidos si proliferan las actividades humanas. Sierra Pelada era probablemente la colonia más importante de Europa en el momento en que se iniciaron las labores de plantación de los eucaliptos (Bernis 1966). Pero la drástica reducción de matorral y dehesa a un cinco por ciento de la superficie (Galán 2010) afectó negativamente a la colonia de buitres: el número de parejas se había reducido a cuarenta y cinco a mediados de los años setenta y a veintisiete en 1983, pasando al cuarto lugar de importancia entre las colonias ibéricas de buitre negro.

Desde avanzada la década de 1980 en que el buitre negro es declarado especie protegida y Sierra Pelada Paraje Natural, la Administración andaluza ha requerido a las empresas forestales que realizan trabajos en las plantaciones madereras de la zona que las estacionen, con objeto de no laborar en el Paraje en la estación de nidificación. Los trabajadores de estas empresas han mostrado su rechazo a esta restricción, pues afirman que restringe sus posibilidades de trabajar. De ello ha derivado que estos buitres se hayan convertido en elemento de discordia.

\section{LOS DEFENSORES DEL BUITRE}

Las primeras contestaciones articuladas a la extensión del eucalipto en la sierra llegaron de los conservacionistas de la asociación Ándalus a comienzos de la década de 1980, llamando la atención sobre los perjuicios de esta especie para la flora y la fauna autóctona, en particular para la colonia del buitre negro. Ponen en marcha el Proyecto Buitre Negro "como respuesta a las alarmantes noticias que se tenían sobre el estado de las dos colonias de Buitre Negro" ${ }^{4}$. Los activistas de Ándalus Jesús Vozmediano, Carlos Segovia, Rafael Galán, Enrique Alés ${ }^{5}$ estaban entre las personas que primero se aventuraron a la empresa de salvar a los últimos buitres negros de Sierra

\footnotetext{
${ }^{3}$ Figura legal de protección de espacios agrestes.

${ }^{4}$ Ver Proyecto Buitre Negro en Sierra Pelada en www.asociacion-andalus.org

5 Todos ellos han llegado a ser conocidos y reconocidos después en el activismo medioambiental andaluz y español. Mencionados en distintas publicaciones de divulgación y especializadas, además de autores ellos mismos de estudios sobre el buitre negro u otras temáticas medioambientales, algunas de las cuales citamos en el desarrollo del texto.
} 
Pelada. Obtuvieron algunos éxitos iniciales decisivos: dirigieron misivas a distintos responsables públicos, como Alfonso Guerra (Vicepresidente del gobierno entonces) del que tuvieron respuesta, que instó al Instituto para la Conservación de la Naturaleza (ICONA) a suspender los aterrazamientos hasta que se determinase la no afectación de los buitres. Fue decisivo en aquellos años la buena acogida que la prensa provincial y andaluza ${ }^{6}$ dio a las denuncias que realizaban los ecologistas, pues la fuerza numérica de la asociación y su capacidad de movilización no era suficiente para otro tipo de actuaciones públicas, y en los pueblos no entendían todavía el significado de sus protestas, o se mostraban directamente hostiles, pues en palabras de Carlos Segovia, la imagen de los ecologistas era la de "los que venían a defender al buitre y a quitarle trabajo a la gente ${ }^{7}$. La prensa fue por tanto la fuerza de Ándalus en su defensa de la colonia del buitre negro, especialmente durante los años ochenta.

En 1984 se produce otro hito decisivo en el proceso de reconocimiento de la colonia de Sierra Pelada: miembros del Comité Central de la LVPN (Liga Suiza para la Protección de la Naturaleza), llamada después PRONATURA VAUD contactaron con Javier Castroviejo, entonces Director de la Estación Biológica de Doñana. Los conservacionistas suizos querían avistar buitres negros y visitar una colonia. Castroviejo los puso en contacto con Ándalus. El resultado de aquel encuentro fue la publicación de un artículo en una conocida revista ecologista suiza, que era una llamada de socorro sobre la situación del buitre negro en Andalucía: Sauvons les derniers Vautours moines d'Andalousie! (Trüb 1985). Los conservacionistas de Suiza y del Fondo de Intervención para las Rapaces francés (FIR) tomaron como propio el Proyecto Buitre Negro. En 1989 la Administración andaluza reconoce Sierra Pelada como Paraje Natural con 12.226 hectáreas ${ }^{8}$. El objetivo que motiva la declaración es la protección de la colonia del buitre negro. Pero el reconocimiento legal no ha puesto fin a los problemas para la colonia de estas aves carroñeras: incendios, envenenamientos y nuevas repoblaciones, algunas de ellas dentro del mismo Paraje, han incidido para que no aumente el número de ejemplares, por lo que a principios de la década de 1990 la colonia cedió el cuarto puesto en el ranking europeo a la colonia de la Sierra de Gredos (Ávila).

En 1996 los ecologistas deciden quejarse ante el Comisario Europeo de Medio Ambiente, por lo que consideran dejadez o incluso negligencia de la Junta de Andalucía en su responsabilidad de proteger el Paraje. La denuncia surte efecto y la Administración andaluza reacciona: crea la Comisión de Seguimiento del Buitre Negro e integra a los representantes de Ándalus en dicha Comisión? . Desde entonces, la Delegación de Medio Ambiente prescribe a las empresas madereras que actúan en el Paraje y sus aledaños la prohibición de realizar labores durante el período de cría de

${ }^{6}$ En la sección de Noticias de la página Web de Ándalus (www.asociacion-andalus.org) podemos encontrar una amplia muestra de noticias sobre esta problemática aparecida en distintos medios de comunicación onubenses y andaluces.

7 Entrevista a Carlos Segovia, activista de Ándalus, 2012.

${ }^{8}$ Ley 2/1989, de 18 de julio (BOJA núm. 60, de 27/07/1989).

${ }^{9}$ Los ecologistas proponen que la repoblación se realice sin máquinas; porque se ofertará más trabajo y porque, además, se reducirá la erosión. Los escasos cauces de contacto entre los activistas y los trabajadores, a lo que seguramente hay que añadir el poco interés de los poderes públicos por mejorar la imagen de los ecologistas, se ha traducido en el desconocimiento en las localidades de estas propuestas, manteniéndose la creencia en su insensibilidad al desempleo. 
las parejas. Pero la limitación ha elevado el tono de las críticas y el rechazo por parte de los trabajadores hacia "los ecologistas", a quienes han venido culpando como responsables del desempleo.

En los últimos años ha mejorado sensiblemente la situación de la colonia y en 2015 ha aumentado el número de parejas un 10,5\% respecto al balance de 2014, hasta alcanzar las 105 parejas, según señala el informe sobre el censo de esta especie en la provincia onubense que preparan cada año las organizaciones ecologistas Fundación Bios y Ándalus, con la Junta de Andalucía, en el marco del Proyecto Buitre Negro ${ }^{10}$. A pesar de la mejoría que se ha venido manifestando en los últimos años, Ándalus y Ecologistas en Acción han insistido en graves incumplimientos en la gestión de las fincas dentro y en los límites del Paraje, y hacen un balance negativo de la gestión de los poderes públicos en su responsabilidad de velar por la conservación de la colonia ${ }^{11}$. Sostienen, además, que las autoridades están permitiendo el aumento de la actividad forestal en el hábitat del buitre negro. Justo cuando la Delegación onubense afirma que el buitre negro ya no está en peligro de extinción y su situación mejora en Andalucía y en Sierra Pelada en particular, la asociación Ándalus en Sierra Pelada o Ecologistas en Acción en la comarca del Andévalo ${ }^{12}$ levantan la voz de alarma ante lo que entienden como atentados a espacios protegidos por campañas agresivas de repoblación con eucaliptos. Todo ello decide a los responsables de Ándalus al envío de nuevo quejas a la Comisión Europea (mayo y agosto de 2010). En esta ocasión, sin embargo, la Comisión rechaza tramitar las quejas, pues consideran que las acciones denunciadas no han afectado significativamente a la colonia del buitre negro. Esto constituye un gravísimo error según Ándalus, y un revés preocupante en la lucha por la colonia de Sierra Pelada: tenían la esperanza de que las autoridades europeas corrigieran de nuevo la dejadez o, según ellos, connivencia de la Administración andaluza con los intereses madereros. En definitiva, en el discurso ecologista, el futuro de Sierra Pelada y sus buitres no está garantizado.

Los activistas de Ándalus visitan periódicamente la colonia, y hacen un seguimiento de los ejemplares y los trabajos forestales. Compaginan esta dedicación con una labor sistemática de estudios de legislación ambiental y reglamentos, de denuncias ante diversas instancias, comunicaciones con las autoridades y responsables de las empresas madereras, escritos de prensa y estudios, divulgativos unos, para revistas especializadas otros (www.asociacion-andalus.org). Se trata de un trabajo laborioso, realizado por un reducido grupo de personas, pero sostenido durante muchos años, y que avanza contra la corriente abrumadoramente dominante en la comarca, en la plena consciencia de

\footnotetext{
${ }^{10}$ ver noticia de Huelva Información del día 31 de enero de 2016: http://www.huelvainformacion.es/article/provincia/2208467/buitre/negro/marca/su/mejor/registro/sierra/pelada.html

${ }^{11}$ Ver denuncia de Ándalus ante la Comisión Europea en: http://www.asociacionandalus.org/ andalus/index.php?option=com_docman\&Itemid=76 y noticia de Huelva Información del 9 de febrero de 2014: http://www.huelvainformacion.es/article/provincia/1705226/alerta/por/rey/sierra/ pelada.html

${ }^{12}$ La denuncia de Ecologistas en Acción ante la Fiscalía onubense se presentó el 31 de agosto de 2009, por una acción de desmonte y destoconado realizado por Silvasur, empresa del grupo ENCE, en el Paisaje Protegido del Rio Tinto. Según Juan Romero, representante de Ecologistas en Acción, la actuación, tolerada por Medio Ambiente, suponía que se pasaba “de paisaje protegido a desierto protegido".
} 
la incomprensión circundante. Solo esporádicamente, para faenas específicas como el anillamiento de aves, han estado acompañados por grupos de voluntarios venidos en buena parte de fuera de la comarca, fundamentalmente de la capital andaluza. En nuestra convivencia con ellos, hemos constatado la profunda convicción que les mueve y la determinación inquebrantable de "salvar" a los buitres de Sierra Pelada. Qué resortes animan estas vocaciones y sobré qué referentes y comunidades se asientan es algo a lo que intentaremos aproximarnos en el apartado final.

El trabajo de campo nos ha permitido constatar las condiciones de incomprensión y aislamiento en las que han venido desarrollando su labor los activistas. Unas condiciones de las que son conscientes. En este sentido, es muy revelador el silencio clamoroso con que se recibió en los pueblos aledaños al Paraje la muerte en 2012 de Carlos Segovia: ninguna mención oficial, ningún acto público en su memoria. E igual en el conjunto de una provincia en la que la sombra de los eucaliptos es alargada. Su amigo, el escritor Antonio Rodríguez Almodóvar, dio noticia de su fallecimiento en un diario sevillano:

... se nos ha ido, tras un duro forcejeo con el ave invisible de la muerte, Carlos Segovia..., uno de los más destacados ornitólogos y ecologistas sevillanos. Conductor muchos años de la asociación Ándalus..., fue luchador incansable por los derechos de la naturaleza herida en todos los frentes posibles. Intransigente con los depredadores humanos... Luchar por aquello que realmente amamos fue su lema de campaña, que llevó a incontables proyectos de recuperación, entre los que destaca el del buitre negro de Sierra Pelada... Inolvidable su paciencia en el campo, su minuciosa sabiduría sobre aves de todas clases, su entusiasmo... (El Correo de Andalucía 3 ene. 2013).

La familia de Carlos Segovia y los miembros de Ándalus decidieron cumplir su voluntad y llevar sus cenizas a Sierra Pelada. Al acto íntimo y mínimo de la colocación de una placa en el cerro más alto de Sierra Pelada asistieron sus familiares, miembros de Ándalus y solo un par de personas naturales de dos de los municipios colindantes y miembros de la asociación: Rafael Galán y Antonio Rodríguez "Chamizo". El simbolismo del acto nos revela la tenacidad y perseverancia del conservacionismo en su vocación de resignificar el territorio y la vida silvestre. El rito mortuorio es a la vez un acto de enraizamiento afectivo y de reivindicación significativa: Sierra Pelada debe ser la morada de los buitres y el panteón de sus defensores. Algo así como un santuario del modo nuevo de concebir el mundo que trae consigo el ecologismo.

\section{LAS SOCIEDADES LOCALES: ENTRE EL BUITRE Y EL EUCALIPTO}

La visita turística a los pueblos colindantes de Sierra Pelada (Aroche, Rosal de la Frontera, Cortegana, Almonaster la Real y Santa Bárbara) se realiza por lo general de espaldas al Paraje y sus buitres: la mayoría de los turistas se marchan sin haber conocido la existencia de este patrimonio natural. En los folletos informativos y carteles del viario, el espacio reservado al Paraje es mínimo o inexistente. La estampa majestuosa del vuelo del buitre no está en ningún sitio y para verla hay que llegar a los apartados límites del Paraje, donde lo anuncian unos carteles de la Junta de Andalucía. Hay un turismo especializado que viene expresamente a avistar buitres, pero no es gracias a campañas de las autoridades locales, sino a través de publicaciones espe- 
cializadas del mundo ornitológico. La discreción en la comarca en todo lo relacionado con el buitre es uno de los pocos extremos en los que hay consenso entre conservacionistas, autoridades y sociedad local, aunque por razones enfrentadas. Los ecologistas porque quieren preservar el silencio y la soledad de los apartados hábitats del esquivo buitre. Pero los lugareños y autoridades locales soslayan el Paraje por un rechazo más o menos explícito a que el territorio del buitre esté protegido y las labores madereras tengan que adaptarse al comportamiento de los carroñeros. En los pueblos colindantes se ha evolucionado desde la indiferencia hacia estos carroñeros ("siempre han estado ahí y nadie se ha metido con ellos", nos aseguraba un empleado de la empresa maderera Ibersilva), hasta su antipatía actual, no al buitre, sino a las políticas para su protección y a quienes las propugnan. Súmese a ello que el empresariado turístico es muy endeble en estos pueblos y no se conocen iniciativas privadas que pretendan "vender" al buitre como un potencial reclamo turístico.

De manera que, aunque en apariencia hay consenso en preservar la colonia del ruido turístico, en el fondo, y paradójicamente, ello mismo es indicativo de que el conflicto ambiental está planteado en unos términos netamente desfavorables a la perspectiva e intereses de los activistas verdes. Porque falta allí un sector turístico interesado en promocionar y "Vender" al buitre. En ausencia de estos intereses turísticos -que apoyan instrumentalmente la defensa de bienes patrimoniales ante las expectativas de negocio ${ }^{13}$ - la estampa del buitre y de quienes se empeñan en protegerlo genera en el mejor de los casos interrogantes, y a menudo abierto rechazo. Súmese a la ausencia de intereses turísticos la ascendencia en la comarca de las empresas madereras, todas vinculadas al entramado industrial de ENCE (Energía y Celulosa, antigua Empresa Nacional de Celulosa).

Los propietarios de las dehesas que quedan dentro y en el entorno del Paraje no entienden o no comparten tampoco la nueva filosofía que está detrás de la declaración de aquellos montes como espacio protegido y, sobre todo, no obtienen ventajas pecuniarias y sí ciertas limitaciones de acceso, uso y explotación de sus propiedades. Y dan pábulo a esa forma popular y campesina tradicional de erosión sorda y anónima de la autoridad con expresiones del tipo: "hay quien dice que va a cargarse los buitres"; "dicen que le van a prender fuego a aquello", que surgen de manera espontánea y con cierta frecuencia en las conversaciones con los propietarios y, de igual manera, con los trabajadores. Ellos, cual agricultores de nuestro tiempo que son, no conocen otra práctica — ni otra lógica - que el uso del medio con fines crematísticos. (Lewontin 2000; Abad y Naredo 2002; Bernstein 2011) Aunque es posible la coexistencia de esta lógica y de estas categorías sociales propias del orden institucional liberal con otras, como el ecologismo, hay que entender que para cada una de ellas lo fundamental y lo accesorio son lo inverso: lo que es fundamental para el orden institucional liberal, el lucro, es accesorio para el orden institucional del que son confusamente portadores los grupos ecologistas y conservacionistas: la preservación del medio ambiente en condiciones que consideran salvaguardia de la defensa de la vida como un todo en la tierra (Guha 2000; Martínez Alier 2009).

\footnotetext{
${ }^{13}$ Javier Hernández repasa varios casos en la Península Ibérica en los que la patrimonialización de la naturaleza facilita una adaptación del sector turístico que, con el rótulo de sostenible, se presenta como "tabla de salvación" de las poblaciones locales (Hernández 2015: 318-319).
} 
Otro sector social con influencia en el conflicto es el de los asalariados. Son la mayoría de la población, si bien su influjo no es proporcional a su número, pues su posición es subalterna. Pero no es desdeñable, sobre todo en la forma concreta en que está planteado el conflicto que nos ocupa. Los trabajadores han elaborado una respuesta bastante unitaria: el Paraje y sus buitres no oferta trabajo y, además, supone una traba a la oferta de trabajo. Razón de más para que sean reacios al mismo. Su posición es clara, porque bascula en torno a un único eje: la generación de puestos de trabajo asalariado. Otras consideraciones son completamente laterales para ellos ${ }^{14}$. Con todo, es una respuesta no articulada, que no han elevado a los cauces formales previstos para expresar sus demandas de trabajadores, lo que se debe a su escasa sindicación y a que consideran el Paraje no el gran obstáculo, sino uno más de tantos obstáculos que les mantienen postrados. Subrayemos nosotros, en cualquier caso, que la posición de los trabajadores de la comarca en general es convergente con la defendida por los empresarios de la madera, y hasta podría afirmarse que son los trabajadores los amplificadores de la posición de los empresarios madereros en las sociedades locales.

\section{SIMBOLISMOS DEL BUITRE}

Veremos ahora qué lleva a las autoridades a declarar Patrimonio una especie (el buitre negro) y el lugar en que anida (Sierra Pelada). Hay una evidencia etnográfica irrefutable: el buitre negro, al igual que el más abundante buitre leonado, ha tenido escaso interés para los habitantes del lugar ahora y antes. Veremos también qué explica el celo de los conservacionistas en la protección del buitre.

Es una novedad histórica la atribución de valor patrimonial a una especie animal en la sierra. ¿Por qué ese significado? No es suficiente responder que se hace porque está en peligro de extinción - lo que es verdad-. Es necesario entender qué tramas significativas han convertido en relevante la posibilidad de que una especie desaparezca, en este caso el buitre negro, lo que requiere a su vez contextualizar el significado del buitre negro en el marco general de significados atribuidos a la fauna. La perspectiva tradicional y dominante aún hoy establece una jerarquía en la valoración de las especies en función del tipo e importancia (monetaria y laboral) de su aprovechamiento para la sociedad. Grosso modo, la clasificación ha venido siendo ${ }^{15}$ :

\footnotetext{
${ }^{14}$ Hicimos una excursión con varios informantes jubilados, que de jóvenes trabajaron de porqueros y cabreros. Fue una excursión para el recuerdo. Nos referían caminos, topónimos precisos, familias que tuvieron allí sus chozas. Todo era ahora paisaje monótono de eucaliptos. Y allí, con la nostalgia de las vivencias, sí valoraban la pérdida de los lugares, y reconocían la fealdad de los aterrazamientos y los árboles raquíticos, en los que, decían, no anidaban los pájaros, pero justificaban la empresa del eucalipto, porque "había traído trabajo cuando no había nada y la gente se estaba yendo".

${ }^{15}$ La clasificación que proponemos ha sido elaborada a partir de nuestra etnografía: preguntamos a los entrevistados, y suscitamos discusiones con distintos actores sobre qué significaban para ellos los buitres en relación con otros animales del entorno. En no pocos casos, las consideraciones de los informantes se extendieron también al reino vegetal. Un marco general válido para entender los simbolismos naturales como correlato lógico de las relaciones sociales en el marco de las cosmologías puede encontrarse en Douglas (1988). Información sinóptica sobre los signifi-
} 
1) Animales y plantas domesticadas, que requieren ocupación de personas para su aprovechamiento final. Para todas ellas se reconoce socialmente el derecho de propiedad.

2) Animales y plantas "naturales" $\mathrm{O}$ "Silvestres" que son valorados por el alimento o por otros aprovechamientos (pieles); que no requieren ocupación o atención especial para su aprovechamiento, solo recolección, caza o pesca. No se concebían como propiedad de nadie, se hallasen en terrenos privados o en montes públicos o comunales. El dueño reconocido socialmente (más allá de la letra de la ley vigente) es el que cobraba o recolectaba la pieza, el fruto, la planta ${ }^{16}$. En el caso de especies animales, se trata en general de herbívoros u omnívoros (jabalíes) cuando se valora su carne y/o piel, y de carnívoros cuando se valora su piel. No se consume carne de especies predadoras en la región.

3) Animales y plantas "dañinos", "alimañas", "maleza", "malas hierbas". Todas aquellas especies no valoradas en la alimentación y de las que no se obtiene beneficio pecuniario significativo, además de ser competidoras de especies sí valoradas: zorros, lobos, garduñas, rapaces y cualesquiera predadores y competidores de especies apreciadas para caza, pesca o domesticadas; ratas, ratones, conejos, liebres, topos y cualquiera herbívoros que basen su dieta en alimentos vegetales domesticados. Para todas estas especies "competidoras" se aceptaba su captura y cualquier actuación que las mermase. Conejos y liebres comparten las categorías 2 y 3, pues son competidores y, simultáneamente, altamente valorada su carne. Los dos factores sumados debieron contribuir a su condición de piezas predilectas sobre las que no existió ninguna restricción a su caza. Lo mismo puede afirmarse de zorros, garduñas, etc., pero por la piel.

4) Especies animales o vegetales "silvestres", "Salvajes" cooperadoras o neutras para la actividad agraria: sapos, culebras, cuervos, grajos, etc. se cuentan en este grupo. La actitud de la población agraria respecto a este tipo ha sido de indiferencia, sin acciones significativas ni en pro ni en contra de su existencia. No se valoraba su función coadyuvante por asimilarse a la ciega actividad metabólica de la naturaleza. En este cuarto grupo debe incluirse a los buitres ${ }^{17}$.

$\overline{\text { cados atribuidos a }}$ distintos animales en diferentes culturas puede hallarse en Mariño (2014). En el estudio sobre los bestiarios medievales de Morales (1996) se contiene alguna información genérica sobre creencias asociadas al buitre. Por último, Del Campo (2012) propone sugerentes interpretaciones de la simbolización animal en la tradición europea.

${ }^{16}$ Esta norma consuetudinaria se ha sobrepuesto durante buena parte del siglo XX a la legislación de caza, pues los propietarios de cotos solo muy lentamente se han encontrado con fuerza moral frente a los no propietarios para hacer valer un derecho de propiedad sobre todos los bienes que se dan espontáneamente en sus tierras.

${ }^{17}$ Philippe Descola ha intentado desvelar algo así como la gramática elemental subyacente a los diversos modos de concebirse las relaciones hombre-medio en la pluralidad cultural. Según afirma, la tradición occidental moderna, que llama "naturalismo", ha instaurado una discontinuidad ontológica humano-naturaleza, que le lleva a concebir el medio como lo otro, lo que está fuera y, por tanto —añadimos nosotros-, algo que se concibe como un recurso (Descola y Pálsson 2001). El ecologismo, que hunde sus raíces en el romanticismo (Guha 2000) propone una gramática distinta, como evidencia, entre otras, la propuesta de una "ética de la tierra" de Aldo Leopold (2005). 
Las leyes de caza son coherentes con esta clasificación. Así, la Ley de caza de 1879 establecía en su Sección Primera una orden de animales en tres tipos: los fieros o salvajes, los amansados o domesticados y los mansos o domésticos, reconociendo el derecho de propiedad solo para los mansos o domésticos (Pérez, 1991). En el fondo, las legislaciones de caza que se han sucedido desde finales del siglo XIX han supuesto una relativa asimilación de la "fauna natural" al conjunto de especies domesticadas, porque con ellas el Estado reconoce el derecho de propiedad y usufructo de las mismas. Esta legislación incorpora entre sus motivos la valoración de la riqueza faunística y la importancia de su preservación (Pérez, 1991), pero lo hace partiendo de razones meramente utilitarias, es decir, desde la perspectiva de administración de unos recursos que sirven a los fines de las poblaciones humanas. Es difícil encontrar razones de signo ecologista en las legislaciones cinegéticas.

Joan Frigolé (2012) ha analizado las concepciones del espacio agreste en el Pirineo Catalán, pero sus afirmaciones pueden extrapolarse. Según afirma, en el territorio del Parque Natural por él estudiado, se superponen conflictivamente dos concepciones sobre el medio: la concepción campesina tradicional, estructurada conforme a la oposición domesticado/salvaje, y la concepción estructurada sobre la dualidad natural/artificial, proveniente de culturas urbano-industriales. Según él, la visión campesina concibe como un asalto de lo silvestre y salvaje (de la maleza y las alimañas) lo que consideran positivo (recuperación natural) los individuos de habitus urbanos, los neorrurales y los turistas. Para todos estos es central el concepto de paisaje, es decir, la dimensión visual y contemplativa del campo, que les conduce a ver la naturaleza desde una visión estereotipada, institucionalizada y homogeneizada que encierra la persistencia del mito romántico que desde distintas instancias —agencias de turismo, medios de comunicación, parques naturales, etc.- se difunde y vende como mercancía cultural (Del Río 2006). Todavía distingue Frigolé una tercera concepción, que sería un desarrollo con nuevas implicaciones de la perspectiva urbano-industrial sobre el campo. Esta se estructura sobre la oposición biodiversidad/homogeneidad o autóctono/exótico. Es desde esta perspectiva que se justifica por los poderes públicos la declaración de espacios protegidos (Frigolé 2012: 174).

En el caso que nos ocupa encontramos un conflicto similar entre esas concepciones del territorio agreste identificadas por Frigolé. No obstante, hay un ángulo de análisis, que no anula al propuesto por el antropólogo catalán, sino que lo comprende, y creemos fundamental para explicar el tipo de conflictos entre ecologistas conservacionistas y el resto de actores concernidos: nos referimos a la perspectiva que distingue el par patrimonio/recurso. Podemos definir patrimonio como el conjunto de referentes reconocidos por una comunidad identitaria para la expresión de sus valores, principios y fines, o que es postulado como tal por sus actores relevantes. Como tal, el patrimonio es un tipo de propiedad no enajenable (no mercantil), sino vinculada e inherente a la entidad que la invoca (propiedad patrimonial) (Ariño 2002 y 2004; Fernández de Paz 2006; Velasco 2011; Talego, Coca y Del Río 2011; Agudo 2012).

Por contraposición a patrimonio, que son los bienes materiales o inmateriales que simbolizan principios y valores fundacionales, los recursos son los medios que las comunidades consideran válidos para alcanzar y preservar esos principios. Reparemos en esta sencilla definición, pues queremos refutar con ella todos los materialismos y etologismos, según los cuales los recursos son exteriores y dados a las sociedades, 
que se conforman de diferentes maneras pero siempre para mejor proveerlos. No: sostenemos que los recursos — todo lo materiales que quepa concebir- no son algo externo y dado a la configuración institucional de una sociedad, sino que es el orden significativo que la institución instaura el que define algunas clases de objetos o ideas como recursos y otras como patrimonios. No hay ninguna propiedad inherente a los que son definidos como recursos en cada mundo significativo que permita fundar una definición sustantiva de "recurso" ${ }^{18}$. Por tanto, con carácter general solo puede decirse de "recurso" que es todo aquello que es considerado un medio para un fin. Pero es la institución la que provee el fin (representado en sus bienes patrimoniales) y señala los medios adecuados para alcanzarlo (Berger y Luckmann 1986; March y Olsen 1989; March y Simon 1994; Powell y DiMagio 1999). Por tanto, tan arbitrario es considerar recurso el petróleo o el uranio como las conchas del Kula, el tabernáculo de los israelitas, la virginidad de las núbiles, el pubis de las meretrices, el oro del mercader y el oro de los dioses ${ }^{19}$, o el "oro verde" de la industria maderera, etc.

Pues bien, aunque la concepción tradicional del campo concibe la dualidad domesticado/salvaje en los términos en que lo ha explicado Frigolé (2012), es de mayor relevancia observar que, para esa visión, todos los elementos del medio agreste son recursos en un gradiente de mayor a menor importancia según lo que aportan al sostenimiento pecuniario de las poblaciones (el gradiente en cuatro niveles antes expuesto). La diferencia fundamental en este gradiente de importancia del conjunto de recursos venía establecida por la propiedad (privada, comunal o pública), que regía sobre la generalidad de recursos para los que era necesario realizar actividad agraria de los bienes de nadie (res nullius), que regía para el resto de recursos que se obtienen por recolección, caza y pesca. Es esta, precisamente, la diferencia que se corresponde con la dualidad domesticado/salvaje o silvestre que nos propone Frigolé (2012). No existe en la memoria de las poblaciones serranas conciencia de que cualquiera de estas actividades pudiera suponer merma y, menos aún, desaparición de cualquier «especie natural». La visión del medio agreste y sus recursos que ha existido hasta hace solo

${ }^{18}$ Esta concepción de "recurso" choca con la creencia central de la modernidad que sostiene que el ser humano se orienta prioritariamente a su supervivencia y a satisfacer una serie egoísta de necesidades, entre las cuales hay unas principales que son llamadas primarias o materiales. Son todas las creencias materialistas, según las cuales los recursos son algo previo y exterior a los órdenes institucionales. Esos recursos, universales, serían siempre energía y materiales. Según los materialismos, las sociedades humanas se conformarían siempre, aunque en variadas configuraciones, para mejor proveerse de ellos, las fuerzas productivas infraestructurales, como las llamó Marx. Puede encontrarse una síntesis del concepto de recurso que ha madurado en el industrialismo moderno en Vandana Shiva (1997).

19 Se sostiene del oro que reúne propiedades intrínsecas y que todas las sociedades lo han requerido por tales propiedades. Ello ignora que, para Moctezuma por ejemplo, el oro de los objetos que simbolizaban su condición de semidios era un recurso equiparable, por ejemplo, al mármol para Miguel Ángel. El mármol para Miguel Ángel y el oro para Moctezuma eran materias cuyo único valor era expresar, convenientemente moldeadas, belleza y majestad. Otra cosa completamente distinta a lo que era el oro para los aventureros europeos que conocieron a Moctezuma: para éstos el oro era la mercancía de las mercancías, la cambiabilidad absoluta. Hoy diríamos que los de Cortés veían en el oro del buey Tlatoani un recurso mientras que los aztecas veían su patrimonio. Al apropiárselo, los de Cortés cometieron el crimen más horrendo a ojos de los aztecas: la profanación. 
unas décadas hacía impensable la idea de "desaparición de especies" ya que la naturaleza se concebía como un fondo en regeneración perpetua, carente de límites o, al menos, sin límites precisos y contra el que era necesaria la continua actividad humana de "lucha contra alimañas y maleza". Toda roturación era concebida como una ganancia, como una ampliación de frontera que se obtenía de ese fondo de límites ignotos de la naturaleza agreste, del "monte". Y así han sido vistas las actuaciones de la industria maderera en la comarca.

El caso del lobo es ilustrativo al respecto, pues su presencia en aquellos lugares fue común hasta los años sesenta, pero cada vez menos hasta que "dejaron de verse". La gente de más edad recuerda "historias de lobos". No hubo entonces ninguna organización conservacionista que los vindicara. Los serranos de los sesenta y setenta del pasado siglo pensaron que se había vencido al lobo, pero esto significaba para ellos precisamente que se le había obligado a retirarse, de ningún modo que se extinguía. Los lobos venían del fondo ignoto de la naturaleza, adonde se les había forzado a volver $^{20}$. Pero a partir de los años setenta, los lobos que han sobrevivido han mutado de "alimañas" a "compañeros del hombre" ${ }^{21}$, como refiere Frigolé (2012: 180). El cambio que esto encierra no está tanto en la postergación de la visión campesina en favor de la urbana y neorrural, sino en que el lobo ha pasado de ser un competidor por los recursos y él mismo un recurso (su piel) a ser patrimonio, un valor a preservar. Se trata, de algo más, y de mayor calado, que un cambio de lugar de especies animales en los sistemas clasificatorios del medio natural, ya que supone la emergencia de una nueva categoría en esos sistemas clasificatorios, la categoría de patrimonio natural. Categoría inexistente en el imaginario del campesinado europeo tradicional. El ecologismo es portador de una nueva cosmología y es solo en el seno de la misma que cobra sentido la categoría patrimonio natural. No es el paradigma y la cosmología hegemónica, aunque sí está presente y es hecha valer en muchos conflictos por la definición y usos del medio.

Así se demuestra también en el conflicto ambiental en torno al buitre negro que hemos etnografiado. En efecto, hemos constatado que la concepción abrumadoramente dominante en la sierra, prácticamente general, sobre el entorno biótico, lo concibe como un recurso a disposición de la población humana, sea de acceso libre o sea apropiado según cualquier régimen de propiedad. A tal extremo que si el investigador plantea a sus informantes que ha habido y hay otras concepciones sobre el entorno biótico, las respuestas posibles oscilan entre la incredulidad (“Cómo puede ser eso?") y la desconsideración por absurdo ("serían los primitivos", etc.). La lógica de los locales es la traducción a las circunstancias locales de la concepción judeocristiana, recogida en el Génesis, que concibe al hombre como el ser superior y administrador de la creación, y a lo creado, la base material para el sustento y el cumplimiento del cometido del hombre en la tierra (Innerarity 1990: 73). En la concepción judeocristiana, de la que es trasunto la occidental moderna, el medio es enteramente una realidad mate-

\footnotetext{
${ }^{20}$ La reflexión antropológica y las etnografías sobre las concepciones de la naturaleza y las relaciones entre esta y la cultura cuentan en la antropología ibérica con una tradición y con algunos compendios, como el de Pedro Tomé (2009). Y sobre el simbolismo del lobo contamos con el estudio específico de Díaz de Viana (2003).

${ }^{21}$ Entre otros factores, gracias al talento de Félix Rodríguez de la Fuente en sus documentales.
} 
rial, que está ahí, fuera, como algo aparte de lo humano y para que estos se sirvan de él (Krotz 1990; Ingold 1986; Descola y Palsson 2001). Es decir —y esto es lo fundamental-: un medio para un fin, un recurso. Y como tal recurso, realidad desprovista de cualquier dimensión sagrada o numinosa; realidad desencantada, como habría afirmado Weber (1993), o profana, como sostendría Durkheim (2003). En lo que se refiere específicamente a plantas y animales, la tradición judeocristiana es desacralizadora, pues concibe que solo los humanos sean portadores de aura ${ }^{22}$. Y los sacerdotes y pastores de los creyentes del Libro, cuando han tenido conocimiento de creencias que atribuían cualquier participación sagrada a animales o plantas, lo han imputado a la ignorancia de los gentiles (idolatría) o a los efectos maléficos del Diablo ("falsa conciencia"). Queda pues excluida en estas culturas toda forma de zoolatría y fitolatría, ya sea como abominación en las tradiciones religiosas del Libro, ya sea como absurda en la cultura moderna secularizada. Cosa distinta es la distinción que los tres cultos establecen entre alimentos puros e impuros u ocasiones y personas aptas y no aptas para consumirlos. Pero, en sí mismos, los seres vivos de los que proceden los alimentos no son sacros en la tradición judeocristiana ${ }^{23}$ (Douglas 1977; Contreras 2007).

La modernidad supone una acentuación de la idea de dominio del Hombre sobre el Orbe y la consideración de todo él como un recurso a su merced. A tal instrumentalización universal lleva el dogma crecentista, según el cual el mundo es una realidad inacabada (iniciada por Dios o por una explosión, lo mismo da), simple materia prima que concluirá el Hombre con su trabajo (Arendt 1996: 157-164; Naredo 1995: 82-83). Es esta la cosmología que legitima los poderes globales. Y es la cosmología a la que remiten implícitamente, de manera más o menos consciente, todos los sectores sociales y actores concernidos en el entorno por la decisión de declarar Paraje Natural Sierra Pelada y sus buitres, la que explica la incomprensión y el rechazo casi general a la obstinación de los activistas de Ándalus por "Salvar a los últimos buitres negros de Sierra Morena”.

Comprendemos ahora mejor el significado de la declaración de «espacios naturales protegidos", que incorporan un elemento novedoso respecto a anteriores legislaciones: la noción de patrimonio natural. En la legislación del Estado moderno, hasta el reconocimiento social y político (controvertido aún) de la noción de patrimonio natural, las únicas limitaciones o reservas severas a los derechos de la propiedad privada derivaban de la noción de "utilidad social" o "pública" y la regulación del territorio como dominio rústico, urbano o urbanizable, que tienen un sentido muy diferente al que aquí nos ocupa. Por eso, es una novedad que entidades ecologistas hayan demandado protección para espacios y especies en las últimas décadas. Y que el legislador lo haya reconocido. Cuando es concebido como recurso, el campo es un medio para un

${ }^{22}$ No así respecto de lugares y objetos, de los que los tres cultos del Libro ofrecen un amplio repertorio de ocasiones y espacios para la reverencia.

${ }^{23}$ Esto es matizable en parte para judíos y musulmanes en el caso del cerdo, pues está prohibido el consumo de su carne en ambos cultos por ser un animal maldito o tabú, lo que significa que se le atribuye valor sagrado negativo (Fessler y Navarrete 2003). En otras culturas son relativamente frecuentes la atribución de valor sagrado positivo a ciertos animales, como en los totemismos; o el caso de la vaca para los hindúes (Syed 2000). En las culturas precristianas de Occidente sí está documentado el culto a ciertos animales, caso del lobo o el toro (Blásquez 1983; González Alcalde 2006). 
fin, cuando es concebido y, sobre todo, cuando es declarado legalmente patrimonio, se convierte en fin. Ello porque el espacio o especie patrimonializada es considerado depositario de valores o principios esenciales. En el caso de los espacios naturales, valores naturales que se considera deben preservarse más allá o por encima de fines crematísticos o de otro tipo. Los aprovechamientos crematísticos u otros pueden continuar ejerciéndose, pero siempre que se crea que no amenazan la continuidad finalista de los valores que allí se reconocen y sancionan.

Estas políticas de protección de lotes del territorio agreste como parques nacionales, naturales, etc., son objeto de crítica por quienes ven en ello un cierto "despotismo ilustrado", protagonizado ahora por una expertocracia conservacionista, ignorante y desconsiderada de las poblaciones y el conocimiento local. Sostienen que los parques naturales de hoy son, en lo básico, continuidad de las políticas de protección de espacios "salvajes" promovidas por las élites blancas en el Imperio británico y el mundo anglosajón en general desde finales del siglo XIX ${ }^{24}$. La propuesta de Guha, en su historia del ambientalismo puede ser aclaratoria: reconstruye las motivaciones que llevaron a la declaración de los primeros parques nacionales en el mundo anglosajón (Yellowstone en 1872), que serían seguidas décadas después en Europa (Parque Nacional de Covadonga en España en 1916). Según él, los motivos de esos primeros parques no fueron protoecologistas, sino de monumentalismo natural como expresión de la grandeza y riqueza nacionales, y también de la voluntad de las élites de preservarlos como reservas de caza. Estos primeros "monumentos naturales" fueron considerados "Salvajes", procediéndose incluso a expulsar a las poblaciones oriundas. Guha muestra que el conservacionismo y lo que hemos llamado después la sensibilidad ecologista había nacido ya — como lo ejemplifica la obra de John Ruskin o Henry David Thoreau-, pero no influyó en la declaración de esos "monumentos naturales" (Guha 2000). Sin embargo, las luchas por preservar espacios agrestes de quienes llama ambientalistas, al menos desde los años sesenta del pasado siglo, no pueden explicarse como una prolongación de las motivaciones monumentalistas decimonónicas, sino como intentos de frenar el industrialismo. Y los posicionamientos de las poblaciones locales en tales luchas, unas veces del lado de los ambientalistas, pero otras distantes y aun enfrentados, no pueden remitirse ya al maniqueísmo de campesinos oprimidos y depositarios de milenarios saberes locales frente a agentes capitalistas y agencias gubernamentales opresoras (Guha 2000: 76) ${ }^{25}$. En lo que refiere al conflicto ambiental que nos ocupa de Sierra Pelada, no se ahorma desde luego a tal esquema de una

\footnotetext{
${ }^{24}$ Muchos autores argumentan que las políticas ambientales a menudo son reflejo de la concepción dicotómica naturaleza/cultura, y que ello ha conducido no pocas veces a cierta desconsideración de las culturas locales (Descola y Palsson 2001; Escobar 2000; Vaccaro 2005; Santamarina 2009; Arrieta 2010; Beltrán et al. 2008; Beltrán y Vaccaro 2010; Izquierdo 2010; Valcuende 2010). Aunque muchas de las aportaciones de estos estudios son valiosas, a veces caen en una cierta reificación de "lo local" y "lo campesino" en oposición dual al poder, como si este fuese algo exterior a la aldea.

25 Dowie refiere casos en los que el apoyo de diferentes gobiernos a proyectos de ONGs conservacionistas han supuesto desplazamientos más o menos forzados de población; de cómo muchos líderes indígenas consideran enemigas a tales organizaciones. Pero señala también abundantes ejemplos de una lograda colaboración respetuosa entre entidades conservacionistas, de defensa de los derechos humanos y organizaciones indígenas (Dowie 2006).
} 
"población local" cuyo conocimiento es obliterado y sus recursos usurpados por los agentes gubernamentales, las élites conservacionistas o un empresariado ávido de explotar el patrimonio natural.

\section{CONCLUYENDO: “ORO VERDE26" O BUITRE NEGRO. LA FRONTERA DE SIERRA PELADA}

Ya hemos referido que a principios de los años ochenta unos pocos activistas de Ándalus y de la Coordinadora Ecologista de Huelva (hoy Ecologistas en Acción Huelva) lograron parar los buldócer que iban engullendo más y más superficie de la sierra onubense destruyendo la capa vegetal y aterrazando el terreno para sembrar eucaliptos y pinos. Lo intentaron en varios lugares, pero con especial tesón en Sierra Pelada. De no haber sido por ellos, hoy sería probablemente una plantación de eucaliptos. Y aun otras superficies serranas que habrían tenido el mismo destino maderero se libraron en años sucesivos, porque Sierra Pelada ha constituido un hito importante en las políticas de repoblación forestal de las administraciones públicas en Andalucía: sus protestas fueron decisivas en el cuestionamiento de tales políticas, supeditadas a la industria del papel. Todo ello lo protagonizaron un reducido grupo de activistas del ecologismo que, más allá de que se movilicen por ideales o por rutinas utilitarias, es indudable que han estado solos en mitad de las sociedades locales, cual "enemigos del pueblo" ibsenianos. Sierra Pelada se manifiesta, pues, como frontera en litigio entre los sectores partidarios de las plantaciones industriales y los partidarios de la preservación del paisaje, el bosque y la fauna mediterránea. El conservacionismo, representado allí en especial por Ándalus, ha hecho de Sierra Pelada un bastión frente al eucalipto.

¿Pero por qué Sierra Pelada y no cualquier otro de los enclaves serranos amenazados por las plantaciones? La respuesta directa y obvia es que allí anida el buitre negro, una especie amenazada de extinción. Pero esta respuesta merece una aclaración, no tan obvia pero más reveladora: el buitre negro por un lado y el eucalipto por otro presentan cada uno rasgos que les han convertido en símbolos eminentes del ecologismo conservacionista al primero y del crecentismo o productivismo al segundo. Un simbolismo de oposición que se acentúa mutuamente. Sigamos interrogándonos: ¿Por qué el eucalipto (y subsidiariamente el pino de crecimiento rápido) ha alcanzado un simbolismo emblemático en las comarcas de la Sierra y el Andévalo onubense? Porque ha venido a extenderse precisamente por "los montes" y "baldíos", $\mathrm{y}$, en general, por los terrenos en proceso de abandono o marginales para la economía agraria tradicional en la región, provocando con ello un cambio rotundo en el mapa mental de las poblaciones locales sobre el territorio vivido. Hasta la llegada del eucalipto, estos "montes y baldíos" ocupaban el espacio más apartado e impreciso en los mapas mentales de los lugareños, no tanto por lejanía, sino por ser menos transitados y trabajados, más próximos a ese fondo indeterminado de lo agreste ya referi-

\footnotetext{
${ }^{26}$ El escritor y poeta onubense Juan Cobos Wilkins publicó en 1981 en el desaparecido diario Odiel un artículo criticando el "oro verde". Invoca la memoria y otros valores distintos al de la crematística que impulsa los monoculivos madereros. Y pide: "no convirtáis esta tierra en un desierto con olor a pomada contra el catarro" (en referencia al olor del eucalipto).
} 
do; terreno de la "maleza" y las "alimañas", en el que se adentraban si acaso cabreros, arrieros o cazadores esporádicos ${ }^{27}$. En pocas décadas (entre los años cincuenta y noventa del siglo pasado) el eucalipto ha provocado un vuelco en los mapas del territorio y en el interés de los locales, pues su plantación, cuidados y talas han venido a generar trabajo y actividad pecuniaria donde antes había "maleza y alimañas". Por si fuera poco, el eucalipto, según estas concepciones que conciben el territorio como un gradiente de recursos, ha venido a recuperar, a traer al ámbito productivo lo que no lo era; un agente roturador que "gana" para utilidad humana en forma de dinero y trabajo lo anteriormente improductivo. Para los serranos, el eucalipto no solo ha sido un árbol más del que se obtiene rendimiento pecuniario y trabajo como lo son también la encina, el castaño y el olivo, entre otros, sino el único que ha ampliado la frontera productiva. Por tanto, no debe sorprendernos que las empresas madereras que traen el eucalipto hayan sido acogidas con los brazos abiertos por las poblaciones locales, pues unos y otros participan de esta concepción crecentista y, ya lo hemos visto, desencantada del medio.

¿Y por qué el buitre negro ha podido erigirse en el opuesto simbólico del eucalipto? Fundamentalmente porque es una especie amenazada. Pero más: no es cualquier especie amenazada, es una especie amenazada emblemática. Los naturalistas y ornitólogos reconocen que en su mundo no despiertan el mismo interés todas las especies registradas en los catálogos de animales amenazados de extinción: en el mundo de las aves son predilectas las grandes rapaces y los buitres de vuelo majestuoso, los pájaros más grandes que surcan el cielo ${ }^{28}$. Y ya entre los buitres, el negro y el quebrantahuesos $^{29}$ gozan de un plus entre naturalistas, y, en general, amantes de la naturaleza: porque son esquivos y requieren de la soledad y el silencio de lugares apartados de la actividad humana, precisamente los espacios que en la sierra se han llamado montes de maleza y baldíos. Es innegable desde luego el temprano interés de la ornitología en España por el buitre negro, como lo evidencia que tanto Francisco Bernis como José Antonio Valverde, dos personalidades fundamentales en el reconocimiento público y la institucionalización de la ornitología y aún del conservacionismo en España, se ocuparan del tema en fecha muy temprana (Bernis 1966; Valverde 1966) ${ }^{30}$,

${ }^{27}$ La toponimia usual aun hoy en la comarca corrobora esta condición periférica de "montes" y «baldíos»: los nombres para tales lugares son más genéricos y refieren a superficies mucho más amplias que los topónimos para ruedos, huertas y dehesas "limpias" (sin "mancha").

${ }^{28}$ Esto opinaban Javier Toimil y Miguel J. Garrido, biólogos de la Agencia de Medio Ambiente, en 2012. Y algo parecido sostenía Luis J. Sánchez, responsable de comunicación de ENCE, la propietaria de la fábrica de celulosa en Huelva: el eucalipto era, según afirmaba, el elemento negativo para los conservacionistas, y el buitre el positivo. Los autores del compendio más sistemático sobre aves amenazadas en la Península Ibérica, el Libro Rojo de las aves de España, corroboran estas impresiones. Una ojeada a la extensísima bibliografía final del libro permite comprobar el desequilibrio a favor de estudios sobre rapaces y buitres (Madroño et al 2004: 16).

${ }^{29}$ Benigno Varillas lo define así: «buitre con aspecto de águila, grácil y estilizado... Su dieta de patas y esqueletos de cabras y rebecos, su rojo anillo ocular, el antifaz que le cubre el ojo y sobresale bajo el pico, como un mostacho, las alas negras sobre un plumaje naranja intenso y su comportamiento enigmático hacen de él un ser misterioso y especial" (Varillas 2006: 153). Y en Natura, una publicación divulgativa, el buitre negro ha sido llamado "el monje de la dehesa" (Barón y Álvarez 1998).

${ }^{30}$ La implicación de Valverde y Bernis con el buitre negro y Sierra Pelada es más decisiva aun: como se sabe, la actuación de estos dos naturalistas fue clave para evitar los planes del 
interés que ha continuado después con frecuentes censos y estudios (Hiraldo 1974; Galán, Segovia, Martínez y Alés 2003; de la Puente et al 2006).

El mapa mental o imaginario sobre el territorio de los defensores del buitre es discordante, casi invertido al mencionado de las poblaciones locales y madereros, ya que, para los conservacionistas, el valor superior lo tiene precisamente el monte sin actividad laboral, donde tienen lugar los procesos de regeneración espontánea de flora y fauna. Es sobre estos lugares que fijan su atención, realizan censos, registran movimientos de especies, con tal sigilo, paciencia y constancia como solo es posible a quien intuye ahí valor supremo, fuente de vida y belleza. En los activistas que nos hemos encontrado en Sierra Pelada se da sin duda admiración ante aquel apartado paraje y ello explica la pertinacia en su defensa. Realmente, a través de la convivencia con ellos, hemos podido sustanciar la afirmación general de que en el ecologismo late un reencantamiento de lo agreste (Giner 2003), por completo extraño al utilitarismo hegemónico.

Como queda dicho, están solos y son a menudo incomprendidos y rechazados por los locales, pero no aislados. Muy al contrario, participan y se sienten fuertemente vinculados al mundo de la ornitología y, más en general, del conservacionismo, que constituye en sí mismo una comunidad, si bien no radicada topográficamente. En las conversaciones nos hablaban con familiaridad de estudiosos del buitre en lugares remotos por ellos nunca visitados, pero con los que se han encontrado en congresos y convenciones y mantienen contacto frecuente. Estos son sus vecinos y referentes, mientras que los del lugar son extraños pertenecientes a otras comunidades. Esto evidencia que las comunidades en nuestro tiempo son crecientemente desubicadas, pero que no por ello dejan de tener enorme importancia, en particular para explicar la deriva de los nuevos movimientos sociales, como el ecologista (Castells 1998: 145-153; Del Río, Talego y Coca 2012: 223).

Estamos ahora en condiciones de apreciar con mayor sutileza por qué en Sierra Pelada se ha librado, y sigue librándose, una importante batalla en el terreno fundamental de lo simbólico: eucalipto versus buitre negro hacen ahí de significantes, respectivamente, del productivismo maderero y del ecologismo defensor de espacios a salvo de la avalancha roturadora e industrializadora contemporánea; el silencio del buitre negro contra el ruido de los máquinas madereras. O, desde el otro ángulo, la riqueza y trabajo que conllevan las plantaciones de eucaliptos ("oro verde"), frente al bucolismo romántico e improductivo de unos diletantes con empleo - mayoritariamente funcionarios, profesionales independientes, etc.- en un entorno donde el trabajo remunerado escasea. Es, en definitiva, un caso históricamente situado de la lucha de paradigmas, es decir, de determinar cuáles son los principios y cuales los medios adecuados para alcanzarlos: Crecer o cuidar la Creación.

\footnotetext{
Ministerio de desecar Doñana y sembrar eucaliptos y pinos, hasta lograr su declaración como Parque Nacional (Varillas 2004; 2006; Vozmediano 2004; De Juana 2004; Casado de Otaola 2004). Fundaron la Sociedad Española de Ornitología en 1954, y fueron los primeros responsables de la Estación Biológica de Doñana. Pues bien, como nos reconocía Jesús Vozmediano, y relata en sus Memorias (http://memoriasdedonana.blogspot.com.es/), fueron estos pioneros los que desde la Estación instaron a otros "entusiastas de la naturaleza", como él mismo, a fijar la atención en Sierra Pelada y sus buitres.
} 


\section{BIBLIOGRAFÍA CITADA}

Abad, Carlos, José M. Naredo. 2002. “Sobre la modernización de la agricultura española: de la agricultura tradicional hacia la capitalización agraria y la dependencia asistencial", en Juan J. González y Cristóbal Gómez (Coord.), Agricultura y sociedad en el cambio de siglo: 81-142. Madrid: McGraw-Hill.

Agudo, Juan. 2012. "Patrimonio etnológico y juego de identidades". Revista Andaluza de Antropología. 2. Disponible en: http://www.revistaandaluzadeantropologia.org/uploads/raa/n2/jagudo.pdf. Fecha de acceso: 20 mayo 2015.

Arendt, Hannah. 1996. La condición bumana. Barcelona: Paidós.

Ariño, Antonio. 2002. "La patrimonialización de la cultura y sus paradojas en la sociedad del riesgo", en José M. García Blanco y Pablo Navarro (eds.), ¿Más allá de la modernidad? Las dimensiones de la información, la comunicación y sus nuevas tecnologías: 329-354. Madrid: Centro de Investigaciones Sociológicas.

Ariño, Antonio. 2004. "La promoción del patrimonio y la cultura popular". Cultura e participación. Actas dos III Encontros Cultura e Concellos: 51-78.

Arrieta, Iñaki. 2010. "Patrimonialización cultural y natural: un proceso, múltiples aproximaciones", Iñaki Arrieta (ed.), Museos y Parques Naturales: Comunidades locales, administraciones públicas y patrimonialización de la cultura y la naturaleza: 11-20. Bilbao: Universidad del País Vasco.

Barón, Coral y Juan A. Álvarez. 1998. "El monje de la dehesa: buitre negro". Natura. 187: 7-9.

Beltrán, Oriol, José J. Pascual e Ismael Vaccaro. 2008. “Introducción. Espacios naturales protegidos, política y cultura", en Oriol Beltrán, et al (Coords), Patrimonialización de la naturaleza. El marco social de las políticas ambientales. XI Congreso de Antropología de la FAAEE: 11-25. San Sebastián. 2008.

Beltrán, Oriol e Ismael Vaccaro. 2010. "Espacios naturales y especies salvajes. La construcción de la naturaleza como patrimonio en el Pallars Sobirà, Pirineo catalán", en Iñaki Arrieta (ed.), Museos y parques naturales: comunidades locales, administraciones públicas y patrimonialización de la cultura y la naturaleza: 159-190. Bilbao: Universidad del País Vasco.

Berger, Peter y Thomas Luckmann. 1986. La construcción social de la realidad. Madrid: AmorrortuMurguía.

Bernis, Francisco. 1966. "El buitre negro (Aegypius monachus) en Iberia". Ardeola 12: 45-99.

Bernstein, Henry. 2011. "A dinâmica de classe do desenvolvimento agrário na era da Globalização". Sociologias 27: 52-81.

Blásquez, José. M. 1983. Primitivas religiones ibéricas. Religiones prerromanas. Madrid: Ediciones Cristiandad.

Casado de Otaola, Santos. 2004. "Francisco Bernis, memoria de un ornitólogo". Quercus. 218: 30-35.

Castells, Manuel. 1998. La era de la información. Economía, sociedad, cultura, 3 vol. 2. Madrid: Alianza.

Contreras, Jesús. 2007. "Alimentación y religión". Humanitas Humanidades Médicas. 16: 1-22.

Del Campo, Alberto. 2012. Tratado del burro y otras bestias. Una historia del simbolismo animal en Occidente. Sevilla: Aconcagua.

De Juana, Eduardo. 2004. "Francisco Bernis: una vida dedicada a la conservación de las aves". Quercus 218: 28-29.

De la Puente, Javier, Rubén Moreno-Opo y Juan C. del Moral. 2006. El buitre negro en España. Censo Nacional (2000). Madrid: SEO/BirdLife.

Del Río, Ángel 2006. "Castril y los castrileños. Identidad, paisaje y memoria de un pueblo andaluz", en Antonio Teruel. Castril. Visiones de un paisaje. Granada: Ayuntamiento de Castril.

Del Río, Ángel, Félix Talego y Agustín Coca. 2012. "De la protesta: apuntes sobre los nuevos movimientos sociales en Andalucía", en C. Jiménez y J. Hurtado (coords.), Andalucía. Identidades culturales y dinámicas sociales. Sevilla: Centro de Estudios Andaluces.

Descola, Philippe y Gísli Pálsson. 2001. Naturaleza y sociedad: perspectivas antropológicas. México: siglo XXI.

Díaz de Viana, Luis. 2003. El regreso de los lobos. La respuesta de las culturas populares a la era de la globalización. Madrid: CSIC. 
Douglas, Mary. 1977. Pureza y peligro. Un análisis de los conceptos de contaminación y tabú. Madrid: Siglo XXI.

Douglas, Mary. 1988. Símbolos naturales: exploraciones en cosmología. Madrid: Alianza.

Dowie, Mark. 2006. "Los refugiados del conservacionismo. Cuando la biodiversidad implica desterrar a la gente". Biodiversidad 49: 1-6.

Durkheim, Émile. 2003. Las formas elementales de la vida religiosa. Madrid: Akal.

Escobar, Arturo. 2000. "El lugar de la naturaleza y la naturaleza del lugar: ¿globalización o postdesarrollo?", en E. Langer (comp.), La colonialidad del saber: eurocentrismo y ciencias sociales. Perspectivas latinoamericanas: 113-143. Buenos Aires: CLACSO.

Fernández de Paz, Esther. 2006. "De tesoro ilustrado a recurso turístico: el cambiante significado del patrimonio cultural". Pasos. Revista de turismo y patrimonio cultural 4(1): 1-12.

Fessler, David y Carlos. D. Navarrete. 2003. "Meat Is Good to Taboo. Dietary Proscriptions as a Product of the Interaction of Psychological Mechanisms and Social Processes". Journal of Cognition and Culture 3(1): 1-40.

Frigolé, Joan. 2012. "Cosmologías, patrimonialización y eco-símbolos en el Pirineo catalán en un contexto global". Revista de Antropología social 21: 173-196.

Galán, Rafael, Carlos Segovia, Miguel A. Martínez y Enrique Alés. 2003. "La colonia de buitres negros en Sierra Pelada" Quercus 211: 26-33.

Galán, Rafael. 2010. "Historia de Sierra Pelada 1968-2009". Disponible en: <http://www.asociacionandalus.org/andalus/index.php?option $=$ com_docman\&Itemid $=74 \&$ limitstart $=5>$. Fecha de acceso: 20 mayo 2015.

Giner, Salvador 2003. "Piedad cósmica y racionalidad ecológica". Carisma y razón. La estructura moral de la sociedad moderna. Madrid: Alianza.

González Alcalde, Julio. 2006. "Totemismo del lobo, rituales de iniciación y cuevas-santuario mediterráneas e ibéricas". Quaderns de Prehistòria i Arqueologia de Castelló 25: 249-269.

Guha, Ramachandra. 2000. Environmentalism: a Global History. New York: Longman.

Hernández, Javier. 2015. "El turismo como objeto de estudio. Análisis de la producción bibliográfica de los antropólogos españoles del turismo". Pasos. Revista de Turismo y Patrimonio Cultural 13(2): 305-331.

Hiraldo, Fernando. 1974. "Colonias de cría y censo de los Buitres Negros (Aegyius monachus) en España". Naturalia Hispanica. 2: 1-31. Madrid: Instituto para la Conservación de la Naturaleza.

Innerarity, Daniel. 1990. "La comprensión aristotélica del trabajo”. Anuario Filosófico 23 (2): 69-108

Ingold, Tim. 1986. The Appropriation of Nature: Essays on Human Ecology and Social Relations. Manchester: Manchester University Press.

Izquierdo, Jesús. 2010. "Culturas campesinas y conservación del patrimonio natur-rural", en Iñaki Arrieta (ed.), Museos y Parques Naturales: Comunidades locales, administraciones públicas y patrimonialización de la cultura y la naturaleza: 109-134. Bilbao: Universidad del País Vasco.

Krotz, Esteban 1990. "Nueva vuelta al problema cultura-naturaleza. Contribuciones para la discusión del "problema ambiental" desde la perspectiva de las ciencias antropológicas". Relaciones 11(41): 5-30.

Leopold, Aldo. 2005 [1949]. Una ética de la tierra. Madrid: Los Libros de la Catarata.

Lewontin, Richard. C. 2000. "The Maturing of Capitalist Agriculture: Farmer as Proletarian", en Fred Magdoff et al. (eds.), Hungry for profit: 93-106. New York: Monthly Review.

Madroño, Alberto et al., 2004. Libro rojo de las aves en España. Madrid: MMA y Seo/BirdLife.

March, James. G. y Johan. P Olsen. 1989. Rediscovering Institutions. The Organizational Basis of Politics. New York: The Free Press.

March, James. G. y Herbert. A Simon. 1994. Teoría de la organización. Barcelona: Ariel.

Mariño, Xose R. 2014. Diccionario del simbolismo animal. Madrid: Encuentro.

Martínez Alier, Joan. 2009. El ecologismo de los pobres. Conflictos ambientales y lenguajes de valoración. Barcelona: Icaria.

Morales, Dolores C. 1996. "El simbolismo animal en la cultura medieval". Espacio, Tiempo y Forma, Serie III, H. ${ }^{a}$ Medieval 9: 229-255.

Naredo, José. M. 1995. La economía en evolución: Historia y perspectivas de las categorías básicas del pensamiento económico. Madrid: Siglo XXI. 
Pérez, Isabel. 1991. "Legislación cinegética en España: evolución y actualidad». Agricultura y Sociedad 58: 173-186.

Pérez, Juan. D. 2003. "Entre la explotación y la conservación de los recursos naturales: el movimiento conservacionista americano en la segunda mitad del siglo XIX". Historia Actual Online. 1: 57-65. Disponible en http://historia-actual.org/Publicaciones/index.php/haol/article/view/10/ 8. Fecha de acceso: 3 octubre 2016.

Powell, Walter y Paul DiMaggio. 1999. El nuevo institucionalismo en el análisis organizacional. México: FCE.

Santamarina, Beatriz. 2009. "De parques y naturalezas. Enunciados, cimientos y dispositivos". Revista de Dialectología y Tradiciones Populares LXIV(1): 297-324.

Shiva, Vandana. 1997. "Recursos", en Wolfgang Sachs (ed.), Diccionario del desarrollo: 319-336. Cochabamba: Centro de Aprendizaje Intercultural.

Syed, Renate. 2000. "La sacralidad de la comida. Comer lo sagrado. Aspectos religiosos de la conducta alimenticia en el hinduismo", en Perry Schmidt-Leukel (ed.), Las religiones y la comida: 97-149. Barcelona: Ariel.

Talego, Félix, Agustín Coca y Ángel del Río. 2011. "No todo el monte es orégano. Patrimonio y recursos en la gestión de la naturaleza", en Iñaki Arrieta et al. (coords.), Hacia la inmaterialidad del patrimonio. Cultura y conflicto en la producción del patrimonio inmaterial. Actas del XII Congreso de Antropología. León: Universidad de León.

Tomé, Pedro. 2009. "Miradas antropológicas a las relaciones entre naturaleza y cultura. A modo de introducción". Revista de Dialectología y Tradiciones Populares LXIV(1): 7-22.

Trüb, J. 1985. "Sauvons les derniers Vautours moines d'Andalousie". Nos Oiseaux 38: 133-139.

Vaccaro, Ismael. 2005. "Property mosaic and state-making: Governmentality, expropriation and conservation in the Pyrenees". Journal of Ecological Anthropology 9: 4-19.

Vaccaro, Ismael, Oriol Beltrán. 2010. “Un zoo en los Pirineos. Paradojas de la patrimonialización de la naturaleza", en Camila del Mármol y Susana Narotzky (eds.), Los lindes del patrimonio: 169-189. Barcelona: Icaria.

Valcuende, José M. 2010. «Patrimonializando naturalezas a través del turismo: de leones africanos, mariposaurios, albergues y nativos en la amazonia suroriental peruana", en Camila del Mármol y Susana Narotzky (eds.), Los lindes del patrimonio: 149-168. Barcelona: Icaria.

Valverde, José A. 1966. "Sobre buitres negros en Andalucía”. Ardeola 12: 101-118.

Varillas, Benigno. 2004. "Valverde: cómo se forjó un ser único e irrepetible". Quercus 218: 36-38.

Varillas, Benigno. 2006. "El quebrantahuesos, el pájaro de fuego”. Ars Médica. Revista de Humanidades 5(2): 153-165.

Veiras, Xose y Miguel. A. Soto. (coords.). 2011. La conflictividad de las plantaciones de eucalipto en España y Portugal. Análisis y propuestas para solucionar la conflictividad ambiental y social de las plantaciones de eucalipto en la península Ibérica. Madrid: Greenpeace.

Velasco, Honorio M. 2011. "Lugares de memoria y olvido", en Díaz Viana, Luis, Óscar Fernández y Pedro Tomé. (Coords), Lugares, tiempos, memorias. La Antropología Ibérica en el siglo XXI: 249254. León: Universidad de León.

Vozmediano, Jesús. 2004. El espíritu de Doñana. Sevilla: Alaire.

Weber, Max. 1993. Economia y sociedad. Esbozo de sociología comprensiva, Madrid: FCE.

Fecha de recepción: 30 de julio de 2015.

Fecha de aprobación: 3 de mayo de 2016. 